\title{
Changes in the cytokine expression of peripheral Treg and Th17 cells in children with rotavirus enteritis
}

\author{
HUAIFU DONG ${ }^{1}$, SEHUA QU ${ }^{1}$, XIN CHEN $^{1}$, HONGWEI ZHU $^{1}$, XIAOYAN TAI $^{1}$ and JIAHUA PAN ${ }^{2}$ \\ ${ }^{1}$ Department of Pediatrics, The First Affiliated Hospital of Bengbu Medical College, Bengbu, Anhui 233004; \\ ${ }^{2}$ Department of Neurology, Anhui Provincial Hospital, Hefei, Anhui 230000, P.R. China
}

Received July 30, 2014; Accepted April 8, 2015

DOI: $10.3892 /$ etm.2015.2511

\begin{abstract}
The aim of the present study was to investigate the changes in the cytokine expression of peripheral regulatory $\mathrm{T}$ cells (Treg) and T helper 17 (Th17) cells in children with rotavirus (RV) enteritis. In total, 102 children with RV enteritis were recruited for the observation group, while 30 healthy cases were included in the control group. Peripheral blood samples were collected from the individuals in the two groups, after which flow cytometry was conducted to detect the proportion of Treg and Th17 cells. In addition, ELISA was used to determine the levels of the cytokines, interleukin (IL)-10, transforming growth factor (TGF)- $\beta$, IL-17 and IL-6. When compared with the control group, the proportion of Treg cells and level of TGF- $\beta$ in the peripheral blood of the children with RV enteritis were significantly decreased $(\mathrm{P}<0.05)$; however, the proportion of Th17 cells and the serum levels of IL-17 and IL-6 in the peripheral blood of children with RV enteritis were significantly increased $(\mathrm{P}<0.05)$. In conclusion, the present study identified an imbalance in the proportion of peripheral blood Treg/Th17 cells, and subsequently in the expression of cytokines, in children with RV enteritis. Thus, detecting the proportion of peripheral blood Treg/Th17 cells in children with RV enteritis, or the changes in the levels of serum cytokines, is of clinical significance for further investigation into the pathogenesis of RV enteritis.
\end{abstract}

\section{Introduction}

Rotavirus (RV) infection is a common disease worldwide. Although the infection occurs in children and adults, children are more commonly infected. RV is currently the main pathogen that causes severe acute diarrhea in infants (1). In developing countries, $20-50 \%$ of hospitalized children aged

Correspondence to: Dr Jiahua Pan, Department of Neurology, Anhui Provincial Hospital, 139 Jiefang Road, Hefei, Anhui 230000, P.R. China

E-mail: jiahuapancn@126.com

Key words: rotavirus enteritis, regulatory $\mathrm{T}$ cells, T helper 17 cells, cytokine
$<5$ years are infected with RV enteritis, which can lead to the mortality of 600,000 children worldwide each year $(2,3)$. RV primarily affects the epithelial cells of the intestinal villi, resulting in induction of the immune system, predominantly the mucosal immune response. The majority of previous studies have focused on RV infection prevention through humoral immunity, while there are only a few studies investigating cellular immune responses. The majority of the intestinal epithelium is a collection of $\mathrm{T}$ lymphocytes in lymph nodes; thus, investigating the role of antiviral cell-mediated immunity in the gut is particularly important (4). With the increasing number of studies investigating the abnormal immune response and the mechanism underlying RV infection in the body, a variety of cellular immune responses associated with RV cells and cytokines have been demonstrated to be involved in the inflammatory response $(5,6)$. An imbalance in the proportion of regulatory $\mathrm{T}$ cells (Treg)/T helper 17 cells (Th17), and the subsequent expression of cytokines, has become the theoretical basis for the study of various autoimmune disorders and other diseases (7-9). Therefore, the aim of the present study was to examine the changes in the cytokine expression of Treg/Th17 cells in the peripheral blood of children with RV enteritis, in order to further investigate the immunomodulatory effects and clinical significance of the Treg/Th17 imbalance in the pathogenesis of RV enteritis.

\section{Subjects and methods}

General data. In total, 102 children admitted to the First Affiliated Hospital of Bengbu Medical College (Bengbu, China) due to infectious diarrhea between December 2011 and December 2013 were recruited for the study. The children were diagnosed with an RV enteritis infection through polymerase chain reaction inspection, and bowel RV (+) and bacterial culture (-) tests combined with typical clinical manifestations. The infected children had no previous history of disease, had good nutrition and had never used immunosuppressants. Of the 102 children, 59 were male and 43 were female, with an age range between 3 months and 3 years (mean age, $17.5 \pm 6.6$ months). A total of 30 healthy children examined in the hospital during the same time period were selected as the control group. The control group included 19 males and 11 females, with an age range between 2 months and 3 years (mean age, $18.5 \pm 6.5$ months). No statistically significant differ- 
ences with regard to age, gender and weight $(\mathrm{P}>0.05)$ were observed between the two groups. The study was conducted in accordance with the Declaration of Helsinki, and with approval from the Ethics Committee of the First Affiliated Hospital of Bengbu Medical College. Written informed consent was obtained from the participants' parents or guardians.

Sample collection. A fasting venous blood sample $(3 \mathrm{ml})$ was collected from each individual in the two groups in the morning and divided into two parts. One part was used for anticoagulation density gradient centrifugation $(10,000 \mathrm{x} \mathrm{g}$, $10 \mathrm{~min}$, room temperature) to obtain peripheral blood mononuclear cells (PBMCs), for which the PBMC density was adjusted to $2 \times 10^{6}$ cells $/ \mathrm{ml}$ for flow cytometry. The other part was centrifuged at 5,000 x g for $10 \mathrm{~min}$, after which the supernatant was obtained and stored at $-80^{\circ} \mathrm{C}$ for ELISA analysis.

Treg cell detection. A 200- $\mu 1$ sample of cell suspension was added to two test tubes, which were marked as the isomorphic control and the sample. Subsequently, $10 \mu \mathrm{l}$ artificial antigen PerCP-CD4 mAb (BD Biosciences, Franklin Lakes, NJ, USA) and $10 \mu \mathrm{l}$ artificial antigen FITC-CD25 mAb (BD Biosciences) were added to the sample test tube, while $10 \mu 1 \mathrm{PerCP}-\mathrm{CD} 4 \mathrm{mAb}$ and $10 \mu \mathrm{l}$ FITC-Ig-G1 mAb (BD Biosciences) were added to the isomorphic control tube and mixed. The test tubes were incubated in the dark at room temperature for $30 \mathrm{~min}$, and flow cytometry (FC 500; Beckman Coulter, Inc., Miami, FL, USA) was conducted following washing and resuspension, using CXP software (Beckman Coulter).

Th17 cell detection. A $2 \times 10^{6}$ cells/ml sample of PBMC suspension was added to a 24-well culture plate, with $1 \mathrm{ml}$ in each well. Phorbol myristate acetate $(20 \mathrm{ng} / \mathrm{ml}$; Sigma-Aldrich, St. Louis, MO, USA), ionomycin (1 $\mu \mathrm{g} / \mathrm{ml}$; Sigma-Aldrich) and monensin ( $2 \mathrm{nmol} / \mathrm{m} 1$; Sigma-Aldrich) were added to each well and the plates were incubated in a $\mathrm{CO}_{2}$ incubator at $37^{\circ} \mathrm{C}$ for $4 \mathrm{~h}$. Subsequently, the cells were collected and divided into isomorphic control and sample test tubes, after which $10 \mu 1$ PerCP-CD4 mAb was added and the tubes were incubated in the dark at room temperature for $30 \mathrm{~min}$. Following washing with phosphate-buffered saline, the cells were fixed with $4 \%$ paraformaldehyde. The cells were maintained at room temperature for $20 \mathrm{~min}$, parting medium (Dingguo Biotechnology, Inc., Beijing, China) was added and the solution was left for $10 \mathrm{~min}$. Following centrifugation at $10,000 \mathrm{x} \mathrm{g}$ for $10 \mathrm{~min}$ at room temperature, the supernatant was discarded and the cells were resuspended. Next, $10 \mu \mathrm{l}$ PE-IL-17mAb artificial antigen (BD Biosciences) was added to the sample test tube, while $10 \mu \mathrm{l}$ PE-Ig-G1mAb (BD Biosciences) was added to the isomorphic control test tube. The tubes were incubated at room temperature in the dark for $1 \mathrm{~h}$. Flow cytometry (FC 500; Beckman Coulter, Inc.) was conducted following washing and resuspension, using CXP software.

ELISA. With the frozen blood serum, ELISA kits were used to detect the levels of interleukin (IL)-10, transforming growth factor (TGF)- $\beta$, IL-17 and IL-6, according to the manufacturer's instructions (R\&D Systems, Inc., Minneapolis, MN, USA). Three repeated wells were set for each sample and standard product, and the optical density was measured at $492 \mathrm{~nm}$ using a microplate reader (Bio-Rad 680; Bio-Rad, Inc., Hercules, CA, USA).

Statistical analysis. All data were analyzed using SPSS 13.0 statistical software (SPSS, Inc., Chicago, IL, USA). Measurement data were analyzed using the t-test and are expressed as the mean \pm standard deviation. The count data were analyzed using the $\chi^{2}$ test. $\mathrm{P}<0.05$ was considered to indicate a statistically significant difference.

\section{Results}

Changes in the proportion of Treg and Th17 cells in the peripheral blood of children infected with $R V$. Following the detection of cell surface marker molecules by flow cytometry, the results revealed that the proportion of Treg cells in children with RV enteritis was significantly decreased when compared with the control group $(\mathrm{P}<0.05)$. However, the Th17 cell proportion was significantly increased in the RV enteritis patients when compared with the control group $(\mathrm{P}<0.05$; Figs. 1 and 2).

Cytokine expression changes in the peripheral blood plasma of children infected with $R V$. ELISA results are shown in Fig. 3. When compared with the control group, the levels of IL-10 and TGF- $\beta$ in the peripheral blood serum of the RV group were significantly decreased $(\mathrm{P}<0.05)$. However, the levels of IL-17 and IL- 6 were significantly increased in the RV group when compared with the control group $(\mathrm{P}<0.05)$.

\section{Discussion}

RV enteritis is the prime cause of infectious diarrhea in infants in China and worldwide. The high incidence rate, acute onset and rapid change of illness have attracted the attention of clinical professionals, and numerous clinical studies have investigated the virological characteristics, infectious epidemiology and clinical control of RV enteritis (10). However, there are few published studies investigating the underlying mechanism of the immune response to RV enteritis, and particularly on cell immunity (11). A number of studies have shown that balances between Thl/Th2 cells and Thl7/Treg cells exist in the body's immune system; the imbalance of which is frequently the basis of certain autoimmune diseases. Th17 and Treg cells have been identified as members of the $\mathrm{CD}^{+} \mathrm{T}$ cell family $(12,13)$. Previous studies have shown that when the Thl/Th2 imbalance theory is unable to account for certain diseases caused by immune system disorders, the Thl7/Treg imbalance theory may provide a subsequent explanation $(14,15)$. The present study found that the proportion of Treg cells in the peripheral blood of children infected with RV enteritis decreased significantly, as compared with the control group, whilst the increase in the proportion of Th17 cells was marked. These observations indicate that a Th17/Treg cell imbalance occurs in patients with RV enteritis, which may be one of the underlying causes of RV.

Thl7 cells are a $\mathrm{T}$ cell subpopulation that has been identified to be different from the Th1 and Th2 subtypes, which secrete IL-17, IL-6 and other cytokines. Th17 cells play an important role in autoimmune diseases, infections, cancer and other 


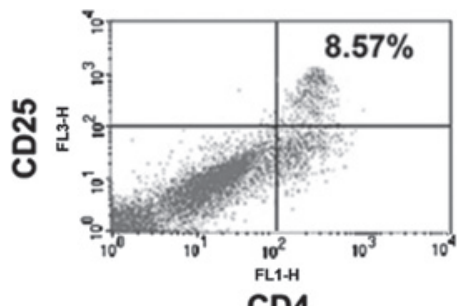

CD4

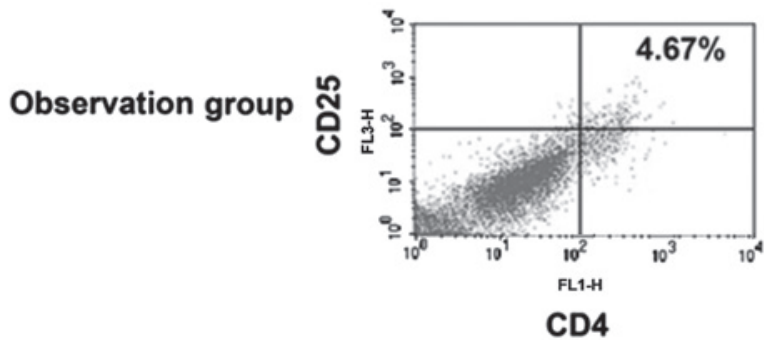

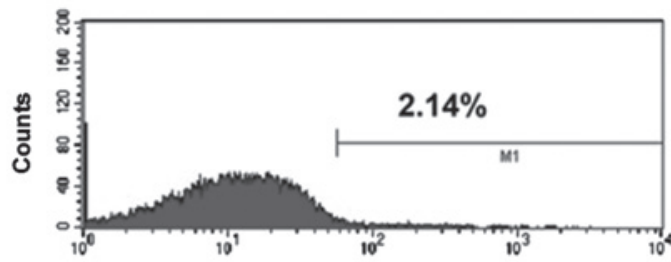

IL-17

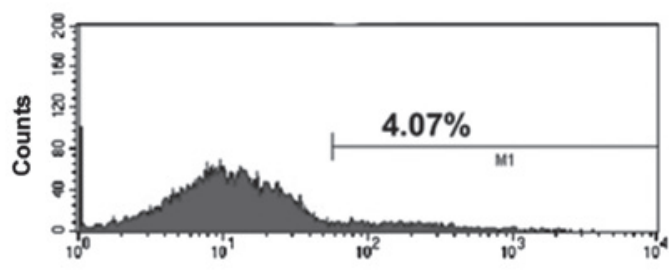

IL-17

Figure 1. Representative figure showing the proportion of regulatory T cells $\left(\mathrm{CD} 25^{+} \mathrm{CD} 4^{+}\right)$and $\mathrm{T}$ helper 17 (IL-17 $)$ cells in the serum samples of the two groups, as determined by flow cytometry. IL, interleukin.

A

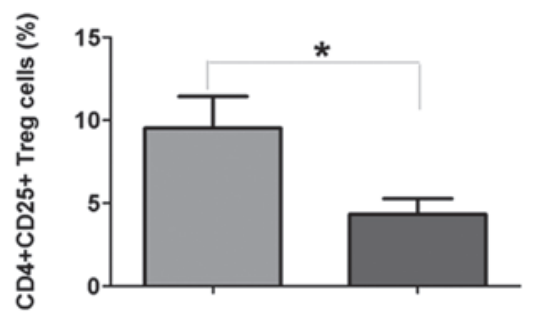

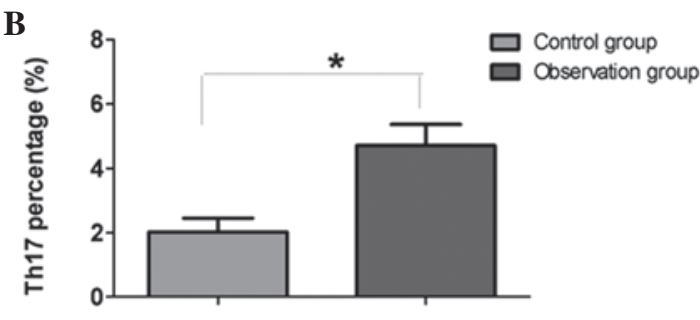

Figure 2. Comparison of (A) Treg cell $\left(\mathrm{CD} 4{ }^{+} \mathrm{CD} 25^{+}\right)$and (B) Th17 cell proportions between the two groups. "P<0.05. Treg, regulatory T cells; Th17, $\mathrm{T}$ helper 17.

A

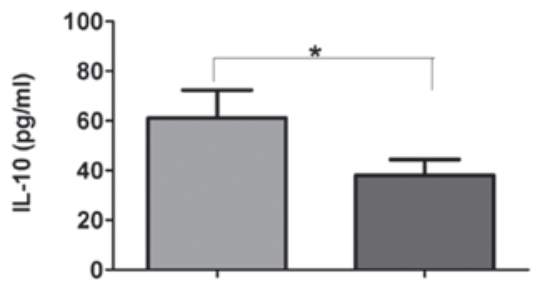

C

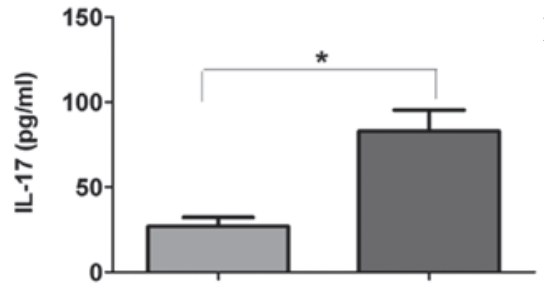

B

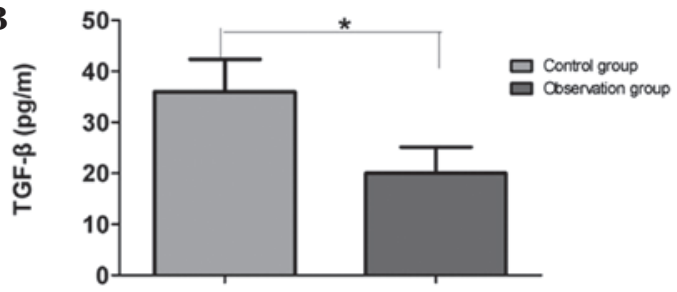

D

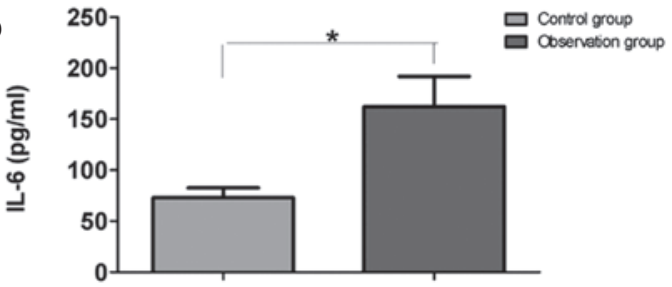

Figure 3. Comparison of the serum levels of (A) IL-10, (B) TGF- $\beta$, (C) IL-17 and (D) IL-6 between the two groups. "P<0.05. IL, interleukin; TGF, transforming growth factor.

diseases (16). Animal models have confirmed their synthesis of the proinflammatory cytokines, IL-17, IL- 6 and TNF- $\alpha$, which are involved in inflammatory response (17). Studies have also hypothesized that Th17 cells play a more important role in the pathogenesis of several inflammatory diseases, as compared with Th1/Th2 cells. IL-17 is a proinflammatory cytokine that can cause the upregulation of chemokines and the invasion of inflammatory cells in tissues $(18,19)$. IL-6 is a pleiotropic cytokine that functions within a variety of cell types, which adjusts a number of aspects of innate and adaptive immunity (20). The present study demonstrated that the expression levels of IL-17 and IL-6 in the peripheral blood of children with RV were significantly increased when compared with the control group.

Treg cells are a T cell subpopulation with immunosuppressive effects that enable active and effective control over the 
function of other immune cells. Changes in the number of Treg cells or inhibition of their activity may result in the occurrence and development of autoimmune diseases (21). Treg cells primarily secrete IL-10 and TGF- $\beta$ (22-24). Kim et al (25) revealed the impact of Tregs on the immune response during RV infection. Furthermore, Chen et al (26) found that detection of the serum level of IL-10 was of great significance for RV clinical diagnosis. Jiang et al (27) also confirmed that IL-6, IL-10 and other cytokines play a potential role in the pathogenesis of RV enteritis. The current study revealed a significant decrease in the levels of IL-10 and TGF- $\beta$ in the peripheral blood of children infected with RV when compared with the control subjects, which is in line with the decrease in the Treg cell proportion in the peripheral blood. Nish et al (28) found that IL-6 exhibited an inhibitory effect on Treg cells, and Hou et al (29) showed that IL-6 and IL-17 promoted viral persistence via the inhibition of apoptosis and the synergistic function of cytotoxic T cells. These results indicate that a Th17 and Treg disorder destroys the basis of the immune balance, exacerbates viral infections and promotes the occurrence of RV enteritis.

In conclusion, an imbalance in the proportion of Treg/Th17 cells and the expression of cytokines in the peripheral blood of children with RV enteritis may be one of the underlying pathogeneses. This conclusion has important clinical value with regard to the detection of Treg/Th17 cells and cytokine expression for the diagnosis, treatment and prognosis judgment of RV enteritis.

\section{References}

1. Enweronu-Laryea CC, Sagoe KW, Damanka S, Lartey B and Amrah GE: Rotavirus genotypes associated with childhood severe acute diarrhoea in southern Ghana: A cross-sectional study. Virol J 10: 287, 2013.

2. Turner A, Ngwira B, Witte D, Mwapasa M, Dove W and Cunliffe N: Surveillance of rotavirus gastro-enteritis in children in Blantyre, Malawi. Paediatr Int Child Health 33: 42-45, 2013.

3. Lesanu G, Becheanu CA, Vlad RM, Pacurar D, Tincu IF and Smadeanu RE: Clinical characteristics of rotavirus diarrhea in hospitalized Romanian infants. Pediatr Infect Dis J 32: 89-91, 2013.

4. Ogden KM, Snyder MJ, Dennis AF and Patton JT: Predicted structure and domain organization of rotavirus capping enzyme and innate immune antagonist VP3. J Virol 88: 9072-9085, 2014

5. Cai HF, Lan JH and Qian LJ: Application of clinical pathways in children with rotavirus enteritis. Zhongguo Dang Dai Er Ke Za Zhi 13: 820-822, 2011 (In Chinese).

6. Medici MC, Abelli LA, Guerra P, Dodi I, Dettori G and Chezzi C: Case report: Detection of rotavirus RNA in the cerebrospinal fluid of a child with rotavirus gastroenteritis and meningism. J Med Virol 83: 1637-1640, 2011.

7. Li S, Li Y, Qu X, Liu X and Liang J: Detection and significance of TregFoxP3(+) and Th17 cells in peripheral blood of non-small cell lung cancer patients. Arch Med Sci 10: 232-239, 2014

8. Huang X, Chen Y, Zhang F, Yang Q and Zhang G: Peripheral Th17/Treg cell-mediated immunity imbalance in allergic rhinitis patients. Braz J Otorhinolaryngol 80: 152-155, 2014.

9. Huang XK, Yang QT, Chen YL, Zhang FC and Zhang GH: Expression of peripheral blood gammadelta $\mathrm{T}$ cells, treg cells and cytokines IL-17 and TGF-beta1 in patients with allergic rhinitis. Zhonghua Er Bi Yan Hou Tou Jing Wai Ke Za Zhi 48: 544-548, 2013 (In Chinese).
10. Zhou R, Xu JL, Wu D and Tang JL: Analysis of prognostic factors for infantile rotavirus infection. Genet Mol Res 14: 790-796, 2015.

11. Medici MC, Abelli LA, Martinelli M, et al: Clinical and molecular observations of two fatal cases of rotavirus-associated enteritis in children in Italy. J Clin Microbiol 49: 2733-2739, 2011.

12. Li L, Zhang SN, Ran JH, Liu J, Li Z and Li LB: Mechanism of immune hyporesponsiveness induced by recipient-derived immature dendritic cells in liver transplantation rat. Chin Med Sci J 26: 28-35, 2011.

13. Shen Y, Hong SL, Hu GH, Tang XY, Kou W and Pan CK: Imbalance of Th17/Treg cell ratio in peripheral blood of patients with nasal polyposis and its clinical significance. Xi Bao Yu Fen Zi Mian Yi Xue Za Zhi 27: 1339-1342, 2011 (In Chinese).

14. Mai J, Wang H and Yang XF: Th 17 cells interplay with Foxp3 ${ }^{+}$ Tregs in regulation of inflammation and autoimmunity. Front Biosci (Landmark Ed) 15: 986-1006, 2010.

15. Shen X, Du J, Guan W and Zhao Y: The balance of intestinal Foxp $3^{+}$regulatory $\mathrm{T}$ cells and Th17 cells and its biological significance. Expert Rev Clin Immunol 10: 353-362, 2014.

16. Cosmi L, Santarlasci V, Maggi L, Liotta F and Annunziato F: Th17 plasticity: Pathophysiology and treatment of chronic inflammatory disorders. Curr Opin Pharmacol 17: 12-16, 2014.

17. Brandenberger C, Li N, Jackson-Humbles DN, Rockwell CE, Wagner JG and Harkema JR: Enhanced allergic airway disease in old mice is associated with a Th17 response. Clin Exp Allergy 44: 1282-1292, 2014.

18. Cosmi L, Maggi L, Santarlasci V, Liotta F and Annunziato F: T helper cells plasticity in inflammation. Cytometry A 85: 36-42, 2014.

19. Han Y, Ye A, Bi L, Wu J, Yu K and Zhang S: Th17 cells and IL-17 increase with poor prognosis in patients with acute myeloid leukemia. Cancer Sci 105: 933-942, 2014.

20. Pal M, Febbraio MA and Whitham M: From cytokine to myokine: The emerging role of interleukin-6 in metabolic regulation. Immunol Cell Biol 92: 331-339, 2014.

21. Cao Y, Li C, Zhang Q, Wang Y and Xia R: Extracellular ubiquitin enhances the suppressive effects of regulatory $\mathrm{T}$ cells on effectot T cell responses. Clin Lab 60: 1983-1991, 2014.

22. Yang X, Gao T, Shi R, Zhou X, Qu J, Xu J, Shan Z and Teng W: Effect of iodine excess on Th1, Th2, Th17, and Treg cell subpopulations in the thyroid of NOD.H-2h4 mice. Biol Trace Elem Res 159: 288-296, 2014

23. Wen K, Li G, Yang X, et al: $\mathrm{CD}^{+} \mathrm{CD}^{-} 5^{-} \mathrm{FoxP}^{+}$regulatory cells are the predominant responding regulatory $\mathrm{T}$ cells after human rotavirus infection or vaccination in gnotobiotic pigs. Immunology 137: 160-171, 2012.

24. Mesa MC, Gutiérrez L, Duarte-Rey C, Angel J and Franco MA: A TGF-beta mediated regulatory mechanism modulates the $\mathrm{T}$ cell immune response to rotavirus in adults but not in children. Virology 399: 77-86, 2010.

25. Kim B, Feng N, Narváez CF, He XS, Eo SK, Lim CW and Greenberg $\mathrm{HB}$ : The influence of $\mathrm{CD}^{+} \mathrm{CD} 25^{+} \mathrm{Foxp}^{+}$regulatory $\mathrm{T}$ cells on the immune response to rotavirus infection. Vaccine 26: 5601-5611, 2008

26. Chen SM, Ku MS, Lee MY, Tsai JD and Sheu JN: Diagnostic performance of serum interleukin- 6 and interleukin-10 levels and clinical predictors in children with rotavirus and norovirus gastroenteritis. Cytokine 59: 299-304, 2012.

27. Jiang B, Snipes-Magaldi L, Dennehy P, et al: Cytokines as mediators for or effectors against rotavirus disease in children. Clin Diagn Lab Immunol 10: 995-1001, 2003.

28. Nish SA, Schenten D, Wunderlich T, et al: T cell-intrinsic role of IL-6 signaling in primary and memory responses. eLife 3: e01949, 2014

29. Hou W, Jin YH, Kang HS and Kim BS: Interleukin-6 (IL-6) and IL-17 synergistically promote viral persistence by inhibiting cellular apoptosis and cytotoxic $\mathrm{T}$ cell function. J Virol 88: 8479-8489, 2014. 